\section{Heterotopic ossification of the vascular pedicle of fibula causing trismus}

\section{Sir,}

The fibula is the most common vascularised bone used for maxillary and mandibular reconstruction. In patients with ectodermal dysplasia, a very rare condition, the fibula can be used for alveolar reconstruction to increase the height of the bone to enable placement of implants for dental rehabilitation. ${ }^{[1]}$ The distal part of the harvested fibula bone is used for reconstruction, while the proximal part is discarded by extra-periosteal dissection. However, during the fine-tuning of the osteotomy, some part of the
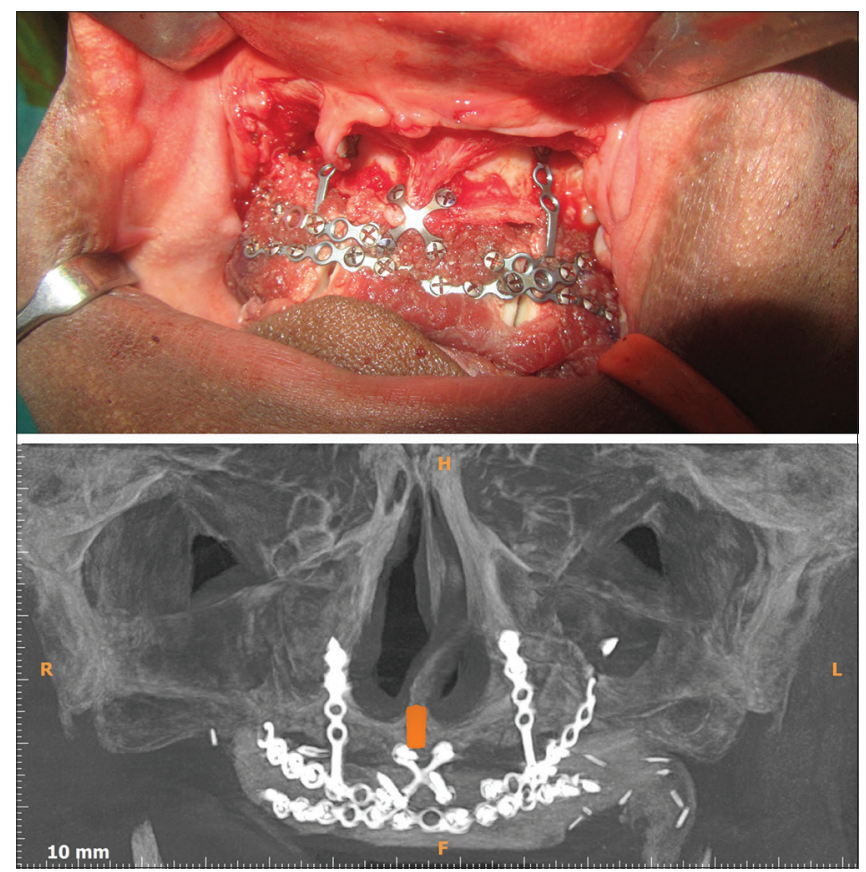

Figure 1: Fixation of free fibula flap for the upper alveolar augmentation and the post -operative orthopantomogram showing the fixation periosteum is retained along the vascular pedicle. This vascularised periosteum attached to the vascular pedicle has osteogenic potential. ${ }^{[2]}$ This heterotopic periosteal ossification is a rare but known phenomenon; ${ }^{[3]}$ however, symptomatic ossification requiring surgical management is uncommon.

We report a case of anhidrotic ectodermal dysplasia, reconstructed with free fibular flap and osseointegrated implants, who developed trismus 2 years after the microvascular reconstruction due to heterotopic ossification of the vascular pedicle.

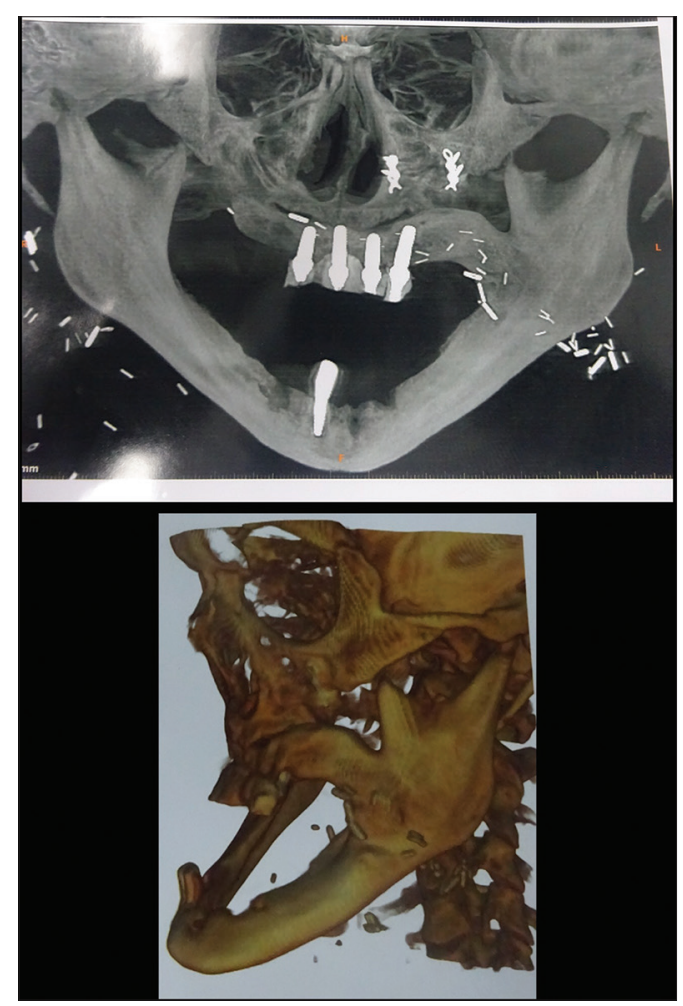

Figure 2: Pre -operative orthopantomogram and three dimensional computer tomography scan showing bony block along the course of vascular pedicle of the free fibula flap 


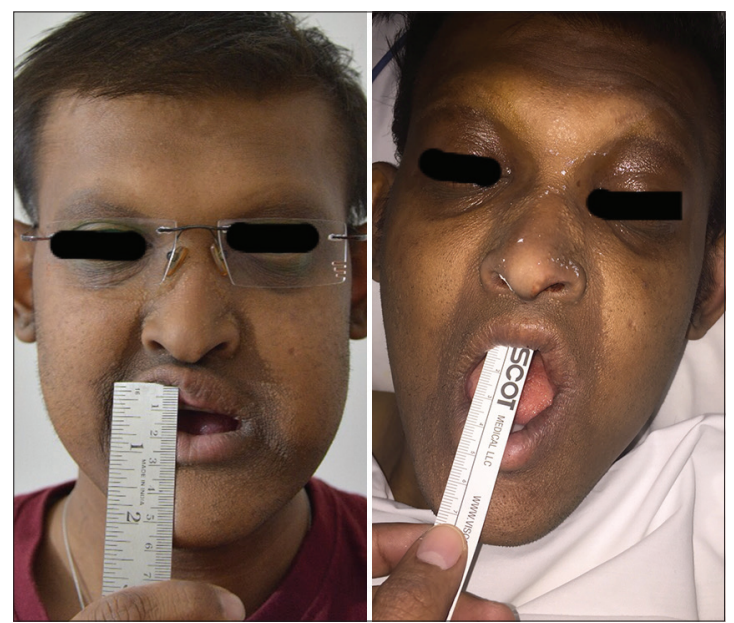

Figure 3: Pre- and immediate post -operative photos of the patient showing improvement in mouth opening

An 18-year-old male patient with anhidrotic ectodermal dysplasia presented to us with the absence of all teeth and underdeveloped upper and lower alveolar ridges. He needed upper alveolar reconstruction, as the alveolar bone thickness below the maxillary sinuses was barely $1 \mathrm{~mm}$. In the lower jaw too, the bone height above the inferior alveolar nerve was not sufficient for the placement of implants. However, in the central segment, between the two mental foramina, the bone height was sufficient for implant placement. In October 2015, a free fibula transfer was performed for the upper alveolar reconstruction with fixation done using titanium miniplates [Figure 1]. In March 2017, the miniplates were removed, and osseointegrated implants were placed in the upper and lower alveolus. His mouth opening at the time was good enough to allow the intraoral manipulation necessary for implant insertion. However, the patient then felt progressively increasing trismus and reduction in jaw movements, until finally, he was unable to move his jaw at all. The orthopantomogram and the computed tomography scan revealed the presence of a bony block on the left side between the reconstructed maxilla and the ramus of the mandible below the coronoid process, along the course of the vascular pedicle [Figure 2]. He was operated on for removal of the bony block under general anaesthesia in January 2018. Through an intraoral incision along the upper gingivobuccal sulcus, extraperiosteal removal of a $1 \mathrm{~cm}$ block of bone from the ossified vascular pedicle was performed. Patient's inter-incisor distance improved from $1 \mathrm{~cm}$ to $4 \mathrm{~cm}$ in the immediate post-operative period, with free movement of the lower jaw [Figure 3]. Histopathology confirmed that the excised block was showing normal bony architecture. Three months after the procedure, the mouth opening

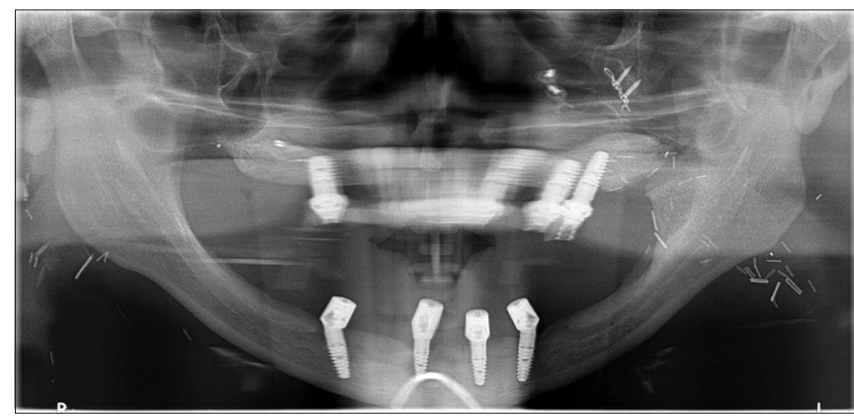

Figure 4: Post- operative orthopantomogram after removal of the bony block showing additional implants being placed

and jaw movements have been maintained and additional implants could be placed in his mandible [Figure 4].

Periosteum preserves its osteogenic potential, even after transposition, especially in a re-vascularised flap. When the fibula is used for maxilla reconstruction, the pedicle is usually routed to the neck near the mandibular ramus. Any periosteum retained with the pedicle is likely to ossify and fuse with the ramus at points of contact, thereby causing restriction of jaw movements, as in this case. Hence, care must be taken while harvesting and shaping the fibula to ensure that the periosteum is cut flush with the fibula, and no part of it stays with the pedicle. ${ }^{[4]}$

\section{Declaration of patient consent}

The authors certify that they have obtained all appropriate patient consent forms. In the form the patient(s) has/have given his/her/their consent for his/her/their images and other clinical information to be reported in the journal. The patients understand that their names and initials will not be published and due efforts will be made to conceal their identity, but anonymity cannot be guaranteed.

\section{Financial support and sponsorship}

Nil.

\section{Conflicts of interest}

There are no conflicts of interest.

Nikunj Mody, Samir Kumta ${ }^{1}$, Shrirang Purohit ${ }^{1}$, Rani Ummul, Sushil Nehete, Leena Jain ${ }^{1}$ Departments of Plastic and ${ }^{1}$ Reconstructive Surgery, Lilavati Hospital and Research Centre, Mumbai, Maharashtra, India

Address for correspondence: Dr. Nikunj Mody, 1G, 91/92, Kalpataru Aura, L. B. S. Road, Ghatkopar West, Mumbai - 400 086, Maharashtra, India E-mail: nikunjbm31@yahoo.in 


\section{REFERENCES}

1. Deshpande SN, Kumar V. Ectodermal dysplasia - Maxillary and mandibular alveolar reconstruction with dental rehabilitation: A case report and review of the literature. Indian J Plast Surg 2010;43:92-6.

2. González-García R, Manzano D, Ruiz-Laza L, Moreno-García C, Monje $F$. The rare phenomenon of vascular pedicle ossification of free fibular flap in mandibular reconstruction. J Craniomaxillofac Surg 2011;39:114-8.

3. Mays AC, Gillenwater AM, Garvey PB. Rare presentation of heterotopic ossification along a fibula free flap pedicle in a high-volume microvascular reconstruction practice. Head Neck 2018;40:E21-E24.

4. Tarsitano A, Sgarzani R, Betti E, Oranges CM, Contedini F, Cipriani $\mathrm{R}$, et al. Vascular pedicle ossification of free fibular flap: Is it a rare phenomenon? Is it possible to avoid this risk? Acta Otorhinolaryngol Ital 2013;33:307-10.
This is an open access journal, and articles are distributed under the terms of the Creative Commons Attribution-NonCommercial-ShareAlike 4.0 License, which allows others to remix, tweak, and build upon the work non-commercially, as long as appropriate credit is given and the new creations are licensed under the identical terms.

\begin{tabular}{|l|l|}
\hline \multicolumn{2}{|c|}{ Access this article online } \\
\hline Quick Response Code: & Website: \\
\hline
\end{tabular}

How to cite this article: Mody N, Kumta S, Purohit S, Ummul R, Nehete S, Jain L. Heterotopic ossification of the vascular pedicle of fibula causing trismus. Indian J Plast Surg 2018;51:252-4.

C 2018 Indian Journal of Plastic Surgery | Published by Wolters Kluwer - Medknow 